\title{
Peripheral Calcifying Odontogenic Cyst: A Case Report and Review of the Literature
}

\author{
Renata Gonçalves Resende • João Artur Ricieri Brito • \\ Leandro Napier Souza $\cdot$ Ricardo Santiago Gomez • \\ Ricardo Alves Mesquita
}

Received: 30 June 2010/Accepted: 4 October 2010/Published online: 16 October 2010

(C) Humana 2010

\begin{abstract}
The peripheral calcifying odontogenic cyst (PCOC) accounts for less than $25 \%$ of the cases of calcifying odontogenic cysts and most commonly appears as a nodule on the gingiva. This paper aims to present both a case report of a PCOC located in the left vestibular maxilla as well as a review of the English-language literature. An 11-year-old female patient presented a swelling in the vestibular region of teeth 12 and 13. Periapical and panoramic radiographs demonstrated irregular calcification. Surgical excision was performed. Microscopic examination showed an odontogenic cystic lesion lined by ameloblastoma-like epithelium, containing numerous ghost cells. Areas of calcification associated with ghost cells could also be observed. The patient was diagnosed with PCOC. The patient has been disease-free for 36 months. The review of the cases of PCOC showed 44 well-defined cases. The mean age was of 49.4 years at the time of diagnosis. The reported cases appeared as a painless swelling, with a slight predilection for females, and were more frequently located in the anterior region of the maxilla or mandible. Surgical excision is the treatment of choice, and recurrence is rare.
\end{abstract}

R. G. Resende · J. A. R. Brito · L. N. Souza ·

R. S. Gomez · R. A. Mesquita

Department of Oral Surgery and Pathology, School of Dentistry,

Universidade Federal de Minas Gerais, Belo Horizonte, Brazil

R. A. Mesquita $(\bowtie)$

Departamento de Clínica, Patologia e Cirurgia Odontológicas, Faculdade de Odontologia, Universidade Federal de Minas Gerais, AV: Antônio Carlos, 6627, SALA 3202-D, Campus Pampulha, Belo Horizonte, MG 31.270-901, Brazil

e-mail: ramesquita@ufmg.br; mesquitara@gmail.com
Keywords Peripheral calcifying odontogenic cyst . Calcifying odontogenic cyst - Calcifying cystic odontogenic tumor - Peripheral calcifying cystic odontogenic tumor

\section{Introduction}

The calcifying odontogenic cyst (COC) is an uncommon odontogenic lesion, which was described by Gorlin et al. in 1962 as a distinct entity [1]. The World Health Organization-2005 (2005 WHO) [2] renamed these lesions as calcifying cystic odontogenic tumors. The COC represents less than $2.0 \%$ of all odontogenic tumors and cysts $[2,3]$. COC presents both in intraosseous (central) and extraosseous (peripheral) locations. The intraosseous COC is a unilocular or multilocular destructive radiolucent lesion that may contain irregular calcifications [4-10]. The peripheral COC (PCOC) represents less than $25 \%$ of the COC [7]. The purpose of this paper is to describe a case of PCOC and to present a review of cases found in English literature from 1962 to 2010.

\section{Case Report}

An 11-year-old female patient was attended to at the Oral Medicine Clinic of the School of Dentistry at Universidade Federal de Minas Gerais complaining of a 6-month swelling in the upper left premolar region. The swelling was firm, painless, and sessile, covered by a normal oral mucosa, and was located in the vestibular gingiva between teeth 12 and 13, which were unerupted (Fig. 1a). No mobility, evidence of infection, or periodontal defect on either tooth near the swelling could be observed. In the 
periapical and panoramic radiographs, no osseous defect was observed. An irregular calcification was noticed between the roots of teeth 12 and 13 (Fig. 1b). The clinical-radiographic differential diagnosis included COC, adenomatoid odontogenic tumor, calcifying epithelial odontogenic tumor, and odontoma. The lesion was surgically removed, and its peripheral nature could be observed, as could a slight osseous erosion of the vestibular cortical bone and the vestibular root of tooth 12 (Fig. 1c). The histological examination revealed a cystic lesion with a fibrous capsule lined by epithelium with cuboidal or columnar palisaded basal cells with dark oval nuclei. The upper epithelial layer was similar to the stellate reticulum. Ghost cells in the epithelial lining and areas of calcification could also be observed (Fig. 2a, b). A diagnosis of PCOC was made. The patient has been disease-free for 36 months.
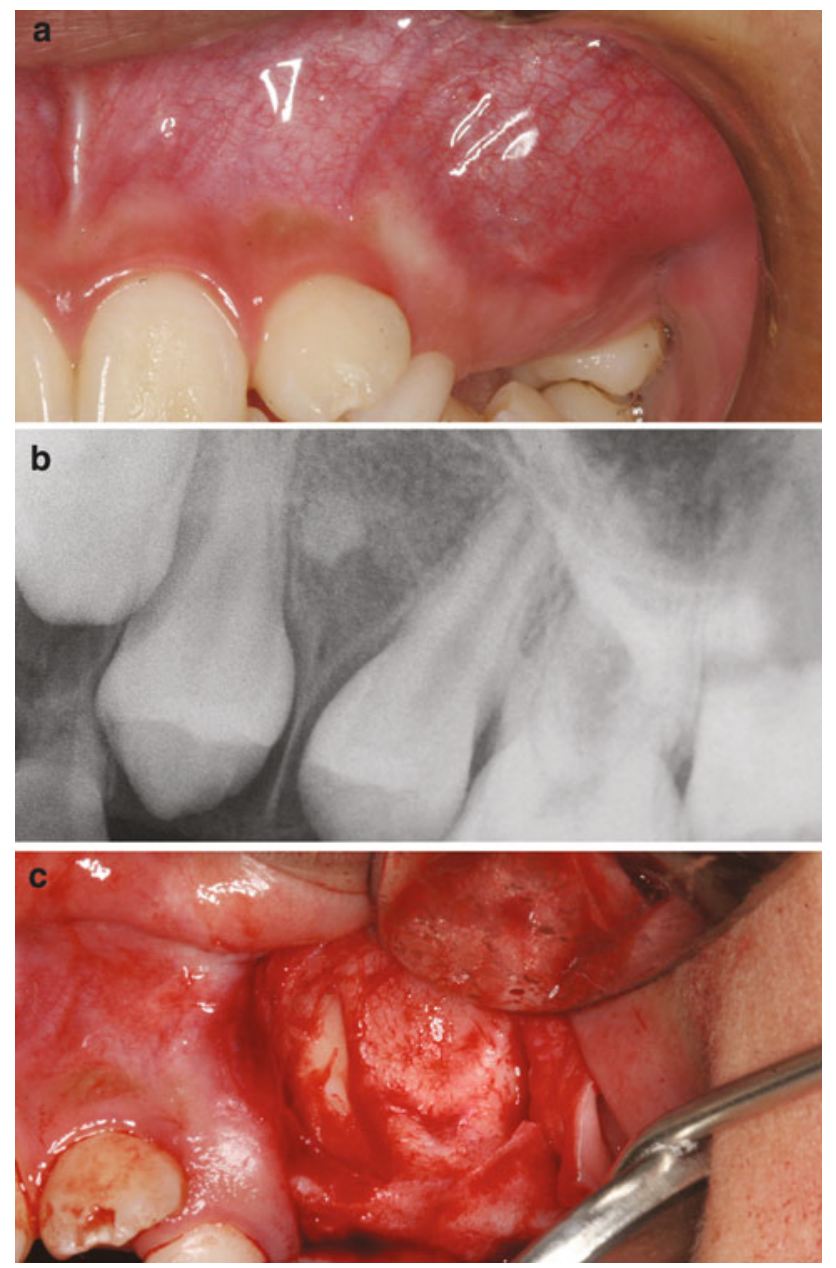

Fig. 1 Clinical and radiographic features of peripheral calcifying odontogenic cyst. a Sessile, swelling covered by a normal oral mucosa in the vestibular region of left posterior maxilla. b Irregular calcification is present between the roots of the teeth 12 and 13 . c After excision a slight osseous erosion of the vestibular cortical bone and the vestibular root of tooth 12 can be seen

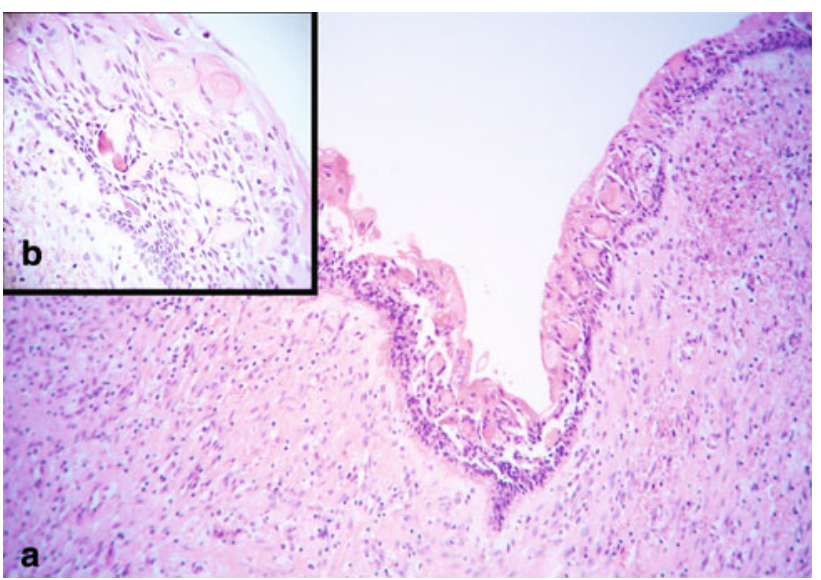

Fig. 2 Histopathology of peripheral calcifying odontogenic cyst. a The lining epithelium and ghost cells (Hematoxylin and eosin stain, original magnification $\times 100$ ). b High power photomicrograph demonstrating collection of ghost cells, some of which exhibit calcification (Hematoxylin and eosin stain, original magnification $\times 400$ )

\section{Discussion}

To review previous case reports of PCOC published in English between 1962 and 2010, a search was carried out in the internet site PUBMED, using the following keywords: Gorlin cyst, calcifying cystic odontogenic tumor, peripheral calcifying cystic odontogenic tumor, calcifying odontogenic cyst, and peripheral calcifying odontogenic cyst. All cases with histological diagnoses of PCOC were included in this review. Peripheral dentinogenic ghost cell tumors were not included. To summarize the data, the review of cases was performed in the following manners: first, the data from reviews carried out in 1991 by Buchner et al. [7] were used; to confirm the information, all works described by these authors between 1962 and 1991 [1, 2, 6-21] were reviewed. Second, the papers from 1991 to 2010 [5, 22-26] were analyzed. Together with this current case report, a total of 44 acceptable cases of PCOC for evaluation and analysis were selected. The data from all cases are presented in Table 1.

The current case presents clinical-radiographic-histological features of a diagnosis of PCOC. Forty-four welldocumented cases of PCOC could be found in the literature, mostly in single reports or reports of a small series of cases. One case of PCOC located in the parotid [8] and one case that presented a clinical analysis of PCOC as an eruption cyst associated with a deciduous tooth [17] were excluded from this analysis. As many studies did not report clinical and radiographic features, either because these were not the goals of the paper or because the reported data was presented as a group, the missing information was classified as "uninformed" in the Table 1. 


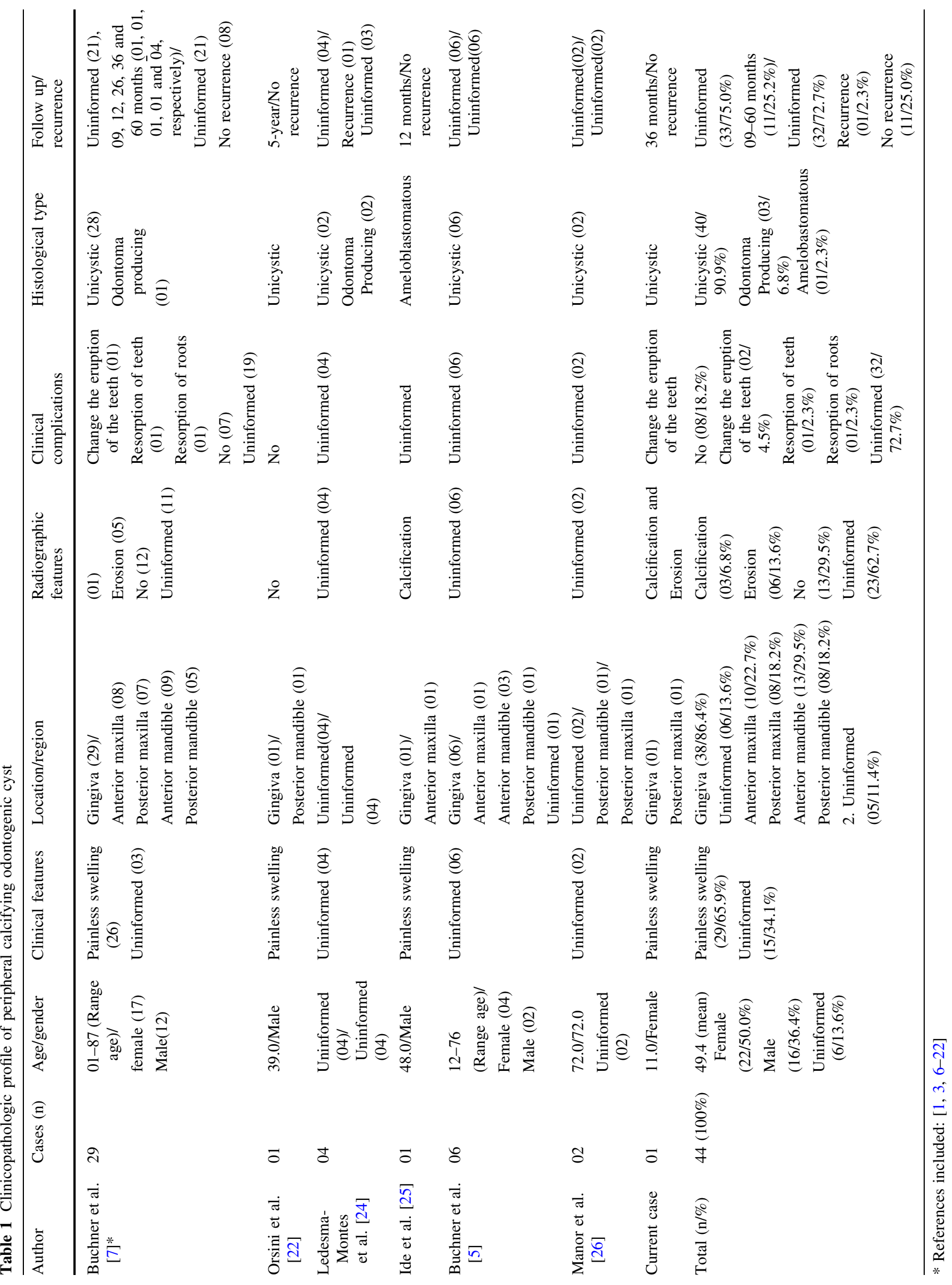


PCOC has been reported to be found between the 1st and 9th decades of life, with a highest incidence occurring in the $6-7$ th decades $[5,8,21]$, and tends to appear with equal frequency amongst males and females. In the current review, the youngest patient was 1 year old, while the oldest was 87 years-old, with a mean of 49.4 years. Gender was identified in 38 cases and 22/38 were female $(58 \%)$. PCOC appears as a painless, firm or soft gingival swelling with no distinct clinical aspects. The clinical differential diagnosis of PCOC includes common gingival growths of a non-neoplastic nature and other peripheral odontogenic tumors [5]. The current case showed an asymptomatic swelling in the vestibular region of teeth 12 and 13. Similarly, a large percentage of the cases reported in the literature were described as painless swellings $(65.9 \%)$ [4, 7]. The clinical presentation was not informed in $34.1 \%$ of the cases.

The mandible is described as the most common site for the PCOC. The most common locations included the incisor-cuspid and the premolar regions, with only a few lesions located in the molar-retromolar region [5]. However, the present review demonstrated a similar distribution throughout the maxillary $(40.9 \%)$ and mandible $(47.7 \%)$ regions. Specifically, 23 cases $(52.3 \%)$ were located in the anterior region: $10(22.7 \%)$ in the maxilla and $13(29.5 \%)$ in anterior mandible. By contrast, $16(36.4 \%)$ cases were seen in posterior sites: $8(18.2 \%)$ in maxilla and $8(18.2 \%)$ in the mandible. Therefore, it can be concluded that the most common location of the PCOC is in the anterior region of the maxilla or mandible [22].

Radiographically, it has been reported that PCOC appears as a radiolucent area with scattered amounts of calcification [17]. However, calcification could only be described in three cases $(6.8 \%)$, while in 23 cases $(62.7 \%)$ this information was not available. The PCOC may cause erosion of the underlying alveolar bone $[5,6,11]$. In this review, the erosion of the underlying alveolar bone was described in 6 cases (13.6\%). In addition, in the present case report, the erosion of the underlying alveolar bone could only be observed during the surgical procedure. The erosion of the underlying alveolar bone in PCOC may be so slight that it does not appear in radiographs and can only be detected during the surgical procedure. Moreover, association with unerupted teeth, root resorption, and tooth displacement can also occur. In the current case report, alteration in teeth eruption could be observed.

Histologically, the PCOC has been described as unicystic, odontoma producing, or ameloblastomatous [2, 3]. In the reviewed case, one $(2.3 \%)$ was reported as ameloblastomatous, three were reported as odontoma producing, and $40(90.9 \%)$ were unicystic. However, this division of the histological types is not highlighted in the WHO-2005 classification. The current case report can be classified as unicystic.

Simple surgical excision is the treatment of choice for PCOC, and recurrence is rare. Follow-up treatment ranged from 9 to 60 months, only one case of recurrence could be observed [24]. In the present case, the patient has been disease-free for 36 months.

In summary, the current paper presents a case of PCOC in an 11-year-old female patient, located in the vestibular region of teeth 12 and 13. After a review of reported cases of PCOC in the English literature since 1962, 44 welldefined cases were found. The mean age was of 49.4 years at the time of diagnosis. The reported cases appeared as a painless swelling, with a slight predilection for the female and more frequently located in the anterior region of the maxilla or mandible. This review provides more solid support to the findings from the literature and improves the understanding of this rare lesion. Moreover, the present case provides further evidence of a non-aggressive behavior of this lesion.

Acknowledgments The authors wish to thank National Council for Scientific and Technological Development (CNPq \#301490/2007-4). Mesquita RA and Gomez RS are research fellows of the CNPq.

\section{References}

1. Gorlin RJ, Pindborg JJ, Clausen FP, et al. The calcifying odontogenic cyst: a possible analogue of the cutaneous calcifying epithelioma of Malherbe: an analysis of fifteen cases. Oral Surg Oral Med Oral Pathol. 1962;15:1235-43.

2. Praetorius F, Ledesma-Montes C. In: Barnes EL, Everson JW, Reichart P, Sidransky D, editors. Pathology and genetics of head and neck tumours. World health organization classification of tumours. Lyon, France: IARC Press; 2005. p. 313.

3. Swan RH, Houston GD, Moore SP. Peripheral calcifying odontogenic cyst (gorlin cyst). J Periodontol. 1985;56:340-3.

4. Moleri AB, Moreira LC, Carvalho JJ. Comparative morphology of 7 new cases of calcifying odontogenic cysts. J Oral Maxillofac Surg. 2002;60:689-96.

5. Buchner A, Merrell PW, Carpenter WM. Relative frequency of peripheral odontogenic tumors: a study of 45 new cases and comparison with studies from the literature. J Oral Pathol Med. 2006;35:385-91.

6. Shamaskin RG, Svirsky JA, Kaugars GE. Intraosseous and extra osseous calcifying odontogenic cyst (gorlin cyst). J Oral Maxillofac Surg. 1989;47:562-5.

7. Buchner A, Merrrell PW, Hansen LS. Peripheral (extraosseous) calcifying odontogenic cyst: a review of forty-five cases. Oral Surg Oral Med Oral Pathol. 1991;72:65-70.

8. Gorlin RJ, Pindborg JJ, Redman RS, et al. The calcifying odontogenic cyst-a new entity and possible analogue of the cutaneous calcifying epithelioma of Malherbe. Cancer. 1964;17:723-9.

9. Bhaskar SN. Gingival cyst and the keratinizing ameloblastoma. Oral Surg Oral Med Oral Pathol. 1965;19:796-807.

10. Jones JH, McGowan DA, Gorman JM. Calcifying epithelial odontogenic and keratinizing odontogenic tumors. Oral Surg Oral Med Oral Pathol. 1968;25:465-9. 
11. Abrams AM, Howell FV. The calcifying odontogenic cyst. Report of four cases. Oral Surg Oral Med Oral Pathol. 1968;25: 594-606.

12. Sauk JJ Jr. Calcifying and keratinizing odontogenic cyst. J Oral Surg. 1972;30:893-7.

13. Fejerskov O, Krogh J. The calcifying ghost cell odontogenic tumor or the calcifying odontogenic cyst. J Oral Pathol. 1972;1: 273-87.

14. Anneroth G, Nordernram A. Calcifying odontogenic cyst. Oral Surg Oral Med Oral Pathol. 1975;39:794-801.

15. Chen SY, Miller AS. Ultrastructure of the keratinizing and calcifying odontogenic cyst. Oral Surg Oral Med Oral Pathol. 1975; 39:769-80.

16. Freedman PD, Lumerman H, Gee JK. Calcifying odontogenic cyst: a review and analysis of seventy cases. Oral Surg Oral Med Oral Pathol. 1975;40:93-106.

17. Praetorius F, Hjorting-Hansen E, Gorlin RJ, et al. Calcifying odontogenic cyst. Range, variations and neoplastic potential. Acta Odontol Scand. 1981;39:227-40.

18. McGowan RH, Browne RM. The calcifying odontogenic cyst: a problem of preoperative diagnosis. Br J Oral Surg. 1982;20: 203-12.

19. Swayer DR, Mosadomi A. Calcifying odontogenic cyst: report of four cases from Nigeria, West Africa. Cent Afr J Med. 1983;29: 196-9.
20. Dominguez FV, Espinal EG. The calcifying odontogenic cyst. Clinical and histological analysis of 10 cases. Acta Odontol Latinoam. 1984;1:77-83.

21. Keszler A, Bruzzone R, Sforza R. Peripheral calcifying odontogenic cyst. Case report. Ann Dent. 1988;47:28-30.

22. Orsini G, Fioroni M, Rubini C, et al. Peripheral calcifying odontogenic cyst. J Clin Periodontol. 2002;29:83-6.

23. Fregnani ER, Pires FR, Quezada RD, et al. Calcifying odontogenic cyst: clinicopathological features and immunohistochemical profile of 10 cases. J Oral Pathol Med. 2003;32:163-70.

24. Ledesma-Montes C, Gorlin RJ, Shear M, et al. International collaborative study on ghost cell odontogenic tumours: calcifying cystic odontogenic tumour, dentinogenic ghost cell tumour and ghost cell odontogenic carcinoma. J Oral Pathol Med. 2008;37: 302-8.

25. Ide F, Mishima K, Saito I, et al. Rare peripheral odontogenic tumors: report of 5 cases and comprehensive review of the literature. Oral Surg Oral Med Oral Pathol Oral Radiol Endod. 2008;106:e22-8.

26. Manor Y, Mardinger O, Katz J, et al. Peripheral odontogenic tumours-differential diagnosis in gingival lesions. Int $\mathrm{J}$ Oral Maxillofac Surg. 2004;33:268-73. 